\title{
Blinds, Education and Mathematics: objeto de aprendizagem sobre as operações básicas da matemática com o uso dos recursos de síntese e reconhecimento de voz
}

\author{
Rafael da Silva Macêdo ${ }^{1}$, Claudia Pinto Pereira ${ }^{1}$, André Luis Bitencourt Fernandes ${ }^{1}$, Kayo \\ Costa de Santana ${ }^{1}$, Ana Jaíze de Oliveira Silva Santos ${ }^{1}$ \\ ${ }^{1}$ Departamento de Ciências Exatas- Universidade Estadual de Feira de Santana (UEFS) CEP - \\ 44036-900 - Feira de Santana - BA - Brasil \\ 3011 rafael@gmail.com, caupinto.sena@gmail.com, deh.oo@hotmail.com,
kayo.santana@hotmail.com, a.jaize@hotmail.com
}

\begin{abstract}
In order to ensure dignity to people, it is essential that their rights are attended even with their different limitations and challenges. The use of new communication and information technologies (ICT) allows a great progress in relation to the inclusion of people in different spheres of society. This way, we present a new version of the BEM tool (Blinds, Education and Mathematics), it is a learning object that enables the teaching and learning of mathematical operations for people with or without visual impairment. Not only helping the socio-digital inclusion of these people, but also with their understanding of mathematics. In this release, besides the voice synthesis, for an information output, BEM presents its new interaction feature: voice recognition. In this article, results of partial tests are also presented that aimed to validate the correct functioning of the application with voice recognition.
\end{abstract}

Resumo.Para garantir dignidade ao ser humano, é imprescindivel que seus direitos sejam atendidos, mesmo diante de suas limitações e dos desafios impostos. $O$ uso de novas tecnologias de comunicação e informação (TIC) possibilitam um grande avanço em relação à inclusão destas pessoas, em diversos âmbitos da sociedade. Neste sentido, será apresentada a nova versão da ferramenta BEM (Blinds, Education and Mathematics), um objeto de aprendizagem que possibilita o ensino e a aprendizagem das operações matemáticas para pessoas com e sem deficiência visual, permitindo, não só a inclusão sociodigital dos sujeitos, como também o auxílio na compreensão da matemática. Nesta versão, além da síntese de voz, para a saída de informações, o BEM apresenta seu novo recurso de interação com o jogo: o reconhecimento de voz. Neste artigo, também são apresentados resultados de testes parciais que objetivaram a validação do correto funcionamento da aplicação com o reconhecimento de voz.

\section{Introdução}

Através de estudos como os vistos em Santana e outros (2016) e Oliveira e Leite (2007), é possível verificar os desafios ainda presentes na educação especial. Os professores ainda não estão capacitados o suficiente para difundir o conhecimento de maneira efetiva para pessoas com algum tipo de deficiência, fazendo com que o conhecimento não seja acessível para todos. Outra questão, tão importante quanto à formação docente, é a falta de recursos adaptados e apropriados para as necessidades próprias de cada tipo 
de deficiência, como, por exemplo, textos em braile, audiobooks, recursos áudio visuais, utilização de linguagem de sinais, dentre outros.

As Tecnologias da Informação e Comunicação (TICs), neste cenário, são ferramentas poderosas para a construção e a difusão de conhecimentos para as pessoas com alguma deficiência, visto que apresentam diversos recursos, tais como: jogos eletrônicos, videoaulas, textos, audiobooks, hardware e softwares adaptados, e outros. Dentre estas ferramentas, estão os objetos de aprendizagem (OA), caracterizados pela IEEE (2002) como qualquer recurso, digital ou não digital, que ofereça suporte ao aprendizado ou treinamento.

Os objetos de aprendizagem digitais se utilizam das TICs para tornar a aprendizagem mais lúdica e prazerosa, favorecendo assim o processo de ensinoaprendizagem e fortalecendo o ensino de diversas competências. Existe uma série deles, inclusive disponíveis publicamente (e.g. RIVED, CESTA, BMT), colaborando com o processo de ensino aprendizagem de diversas disciplinas (Garcia, 2006).

Imbuídos da intenção de favorecer a aprendizagem de matemática, surgiu a ideia de planejar e construir um software, mais especificamente um OA, que ajudasse os estudantes a exercitarem as operações básicas de matemática e os professores a incentivarem o estudo desta competência (i.e. resolver problemas envolvendo as quatro operações com números naturais) de maneira lúdica, dentro ou fora do ambiente de aula. Esse software, chamado de Blinds, Education and Mathematics (BEM), é um objeto de aprendizagem em forma de jogo eletrônico voltado para o ensino das operações básicas da matemática para crianças com e sem deficiência visual.

A dificuldade do ensino aprendizagem de matemática, percebida constantemente nos depoimentos dos estudantes do ensino fundamental, e ratificada pelos estudos de Sanchez (2004), foi um dos motivadores para a idealização deste OA. Além disso, a possibilidade de apoiar os estudos das pessoas com deficiência visual nesta área, e colaborar com a educação especial também motivaram este trabalho e produção.

O BEM, desde a sua primeira versão, conta com funcionalidades de síntese de voz que possibilitam ao usuário com deficiência visual utilizá-lo com facilidade através da recepção de mensagens através da audição (saída de informações), e o uso de teclas de atalho (i.e. teclado) como modalidade de entrada (Macedo et al., 2015). Na segunda versão do software, detalhada neste artigo, foram incluídas funcionalidades de reconhecimento de voz, possibilitando ao usuário mais uma alternativa de interação com o software e, consequentemente, maior facilidade de utilização, principalmente, pelo público com deficiência visual.

Este artigo está dividido em seis seções, além da introdução e referências. $\mathrm{Na}$ segunda seção, fala-se sobre a educação inclusiva e o uso das tecnologias da informação e comunicação na aprendizagem; na terceira seção, é abordado o recurso de reconhecimento de voz; na quarta seção, é apresentada a metodologia utilizada para desenvolver o trabalho, na quinta e sexta seções, são apresentadas, respectivamente, as características do software BEM, e a análise e discussão dos resultados parciais obtidos nos testes realizados com a ferramenta; por fim, são apresentadas conclusões sobre o trabalho juntamente com os trabalhos futuros previstos.

\section{A Educação Inclusiva e o uso das TICs}

A educação inclusiva é um dos grandes desafios que ainda precisam ser trabalhados no sistema educacional, pois a diversidade é um fator inerente a qualquer ser vivo, e por 
direito, essas diferenças não podem ser tratadas como uma barreira ou limitante para a aprendizagem do indivíduo. Para tanto, práticas pedagógicas diferenciadas devem ser somadas às já existentes e utilizadas, de forma a estimular e a criar ambientes propícios para a aprendizagem significativa, e que respondam às necessidades de todos os educandos (Silva, 2011). A inclusão se dá a partir da transposição das barreiras educativas que, de alguma forma, dificultam a aprendizagem, escolhendo e gerenciando os recursos necessários para beneficiar todos, e não somente um grupo (Sanches, 2011).

De acordo com o censo feito em 2010 (IBGE, 2010), estima-se que aproximadamente 35,8 milhões de brasileiros possuem algum tipo de deficiência. Além de estes números serem expressivos, o cenário da acessibilidade e da inclusão no Brasil ainda é bastante precário. Em relação às pessoas com deficiência visual (DV), por exemplo, há um leque de especificidades que necessitam ser contempladas, pois há pessoas com perda total da visão (cegueira) e visão diminuída ou subnormal, e cada nível de deficiência necessita de estratégias e dinâmicas específicas.

Algumas iniciativas são utilizadas para auxiliar as pessoas com DV no seu percurso escolar, tais como a inclusão de salas de recursos nas escolas regulares, os centros de apoio às pessoas com DV (CAP-DV), dentre outras (Araujo e Lopes, 2013), (Resende, 2007). Além destas, outra bastante interessante é o uso de jogos computacionais (TICs), que apoiam os professores, de modo a despertar o interesse e estimular o desenvolvimento dos educandos. Além disso, as TICs têm sido responsáveis pela evolução das relações entre os sujeitos e na forma como eles se comunicam, exercendo um papel importante na comunicação coletiva, dado que possibilitam uma nova maneira de pensar e de se relacionar uns com os outros.

No contexto educacional, o uso de TICs tem por objetivo colaborar com a inclusão social, permitindo o aprendizado de ferramentas de trabalho essenciais para o cotidiano, assim como possibilitando ao estudante uma forma diferenciada de ensino e aprendizagem. Segundo Oliveira, Moura e Sousa (2015, p. 6), "a inserção das TICs no cotidiano escolar anima o desenvolvimento do pensamento crítico criativo e a aprendizagem cooperativa, uma vez que torna possível a realização de atividades interativas". Os autores ainda ressaltam que, além de ajudar o educando a desafiar regras, descobrir novos padrões de relações, possibilita-os inovar e até inserir novos detalhes a outras atividades diferentes, tornando-os assim inovados $\mathrm{e}$ diferenciados.Lima et.al. (2007, p.5) acrescentam, ainda, que "as novas tecnologias de informação e comunicação já se caracterizam como realidade educacional, possibilitando uma mudança brusca no modo de pensar e fazer educação".

Dentro deste cenário, o processo de educação apoiado pelas TICs possibilita o uso de objetos de aprendizagem, que têm por finalidade atuar como recurso didático interativo, envolvendo conteúdos e conceitos de diferentes disciplinas (Santos et. al., 2016). Os OA podem, portanto, ampliar as possibilidades dentro e fora do espaço de sala de aula, funcionando como instrumento lúdico e de auxílio no processo de ensinoaprendizagem (Cunha, 2007). Dentre eles, os jogos computacionais podem contribuir não só para o processo de inclusão dos DV, como também para aquisição de conhecimentos (Araújo, 1997).

Diante deste contexto, destaca-se o uso das TIC no auxílio no processo de ensino aprendizagem de pessoas com DV. O indivíduo com deficiência visual necessita de um cenário educacional que tenha um olhar sensível para suas especificidades, capaz de permitir uma aprendizagem significativa e de qualidade. 
VI Congresso Brasileiro de Informática na Educação (CBIE 2017)

Anais do XXVIII Simpósio Brasileiro de Informática na Educação (SBIE 2017)

\section{Reconhecimento de voz}

A síntese de voz realiza a conversão de texto em fala (áudio), enquanto o reconhecimento de voz/fala é o processo inverso, responsável pela conversão de dados em forma de áudio para texto. Segundo Colombo e outros (2013, p. 3), "o reconhecimento da fala automático consiste em gerar, a partir de um sinal acústico, a representação correspondente que um computador seja capaz de entender".

Qualquer software que dispõe do recurso de reconhecimento de voz/fala automático possui o seu processo de execução sustentado a partir dos dados resultantes do reconhecimento de fala, normalmente representados em forma de texto. A partir destes dados resultantes do processo, o software sucede a tomada de decisões para o seu correto funcionamento.

Normalmente, o processo de reconhecimento de fala é amparado por uma gramática, que estabelece o vocabulário aceito pela aplicação como entrada através da fala. Esta gramática, chamada de gramática de regras, determina as palavras e sentenças as quais o motor de reconhecimento será capaz de decifrar e realizar a conversão para texto. Além deste modelo, há o reconhecimento de fala livre de contexto que independe de uma gramática pré-definida com termos e expressões aceitas. O reconhecimento livre de contexto é capaz de reconhecer qualquer palavra do vocabulário do idioma tratado. Estes tipos de reconhecimento utilizam respectivamente, linguagem de comando e linguagem natural (Sena, 2006).

\section{Metodologia}

$\mathrm{O}$ processo de desenvolvimento do software BEM se iniciou basicamente focado na implementação de uma aplicação com funcionalidade de síntese de voz, a fim de atender demandas de pessoas com deficiência visual, pois seria uma forma de incluí-las no público utilizador da ferramenta. Percebeu-se, após a aplicação dos primeiros testes com a ferramenta (resultados apresentados Santos e outros (2016)), a necessidade de incluir mais uma funcionalidade, o reconhecimento de voz/fala, objetivando a facilitação da utilização da ferramenta, principalmente por pessoas com deficiência visual. O processo de realização dos testes apresentados por Santos (2016) incluiu visitas a uma fundação de amparo às pessoas DV, tendo oportunidade de apresentar a ferramenta a este público.

O passo inicial para inclusão do reconhecimento de voz na ferramenta BEM se deu a partir da revisão bibliográfica em temáticas relacionadas ao processo de reconhecimento de voz e fala e a sua integração em aplicações Java (linguagem de programação utilizada no software), também objetivando a listagem de tecnologias disponíveis e análise da viabilidade da utilização destas. Nessa etapa, foi elaborado um mapeamento das tecnologias disponíveis e suas respectivas possibilidades e limitações. Entre as tecnologias listadas, podem-se destacar: a JLapsApi (Alves, 2015), o Sphinx-4 (Cmusphinx, 2015), o Cloudgarden (Cloudgarden, 2015) e o IBM Via Voice (IBM Via Voice SDK, 2015). Após análise destas tecnologias, decidiu-se que a utilização do IBM Via Voice como motor de reconhecimento de voz seria o mais viável para o projeto, visto que esta tecnologia também já era utilizada na funcionalidade de síntese de voz da ferramenta, se acoplando perfeitamente ao projeto, além de permitir o reconhecimento através de uma gramática pré-definida, que também era um objetivo inicial do projeto.

$\mathrm{O}$ processo de realização de testes se deu continuamente durante o desenvolvimento do trabalho. Além dos testes com resultados publicados por Santos e outros (2016), mais recentemente, com a versão atual do software BEM, foram 
aplicados testes preliminares a fim da validação parcial da funcionalidade do reconhecimento de fala, visto que as outras funcionalidades já haviam sido testadas e validadas anteriormente.

\section{BEM: Blinds, Education and Mathematics}

O software BEM é caracterizado como um OA que visa auxiliar no processo de ensino e aprendizagem das quatro operações básicas da matemática (adição, subtração, multiplicação e divisão). Este OA é acessível por pessoas com deficiência visual, pois é possível a sua utilização com o uso apenas dos sentidos que o indivíduo possui, mais especificamente a audição, o tato e a fala. Na versão anterior, o BEM contava apenas com a síntese de voz, que é o processo de conversão de texto em áudio. Na sua versão mais atual, conta com as funcionalidades de síntese e reconhecimento de voz/fala. $\mathrm{O}$ reconhecimento realiza o processo reverso da síntese, transformando a fala em texto, permitindo, dessa forma, a interação a partir do uso da fala, diminuindo o uso do teclado para a entrada de dados.

$\mathrm{Na}$ versão inicial do BEM, era possível a utilização do software com a inserção de comandos através do teclado do computador, propriedade que, acoplada à síntese de voz, proporciona à acessibilidade por pessoas com DV. Após um tempo, percebeu-se a necessidade de implementação de funcionalidades de reconhecimento de voz para, desta forma, incentivar a sua utilização pelo público DV com maior facilidade. Ou seja, com esta nova funcionalidade, os usuários não são forçados à utilização do teclado, podendo prover comandos ao software apenas através da fala.

O BEM também possui características de um jogo educativo, pois propicia a prática de exercícios matemáticos de forma dinâmica e atrativa. No software, o usuário seleciona a operação matemática que desejar praticar e, em seguida, é submetido à resolução de operações envolvendo tal operação. O jogo é dividido em níveis e subníveis de dificuldade, amparando estudantes do nível inicial do aprendizado a um nível mais avançado, possivelmente em anos escolares mais avançados.

A dinâmica do jogo se dá através da apresentação de um tabuleiro (Figura 1 - A) contendo valores em determinada faixa numérica e com operações envolvendo dois operandos e seu respectivo valor final (resultado) (Figura 1 - B). Assim, o usuário deve encontrar dois números, dentre os valores dispostos no tabuleiro, que satisfaçam o resultado apresentado. Caso o resultado seja positivo, os dois valores são apagados do tabuleiro, e um novo exercício é gerado. O usuário chega ao fim do jogo quando alcança a limpeza de todas as células do tabuleiro. No exemplo exposto na Figura 1, o jogo de multiplicação solicita que o usuário encontre, entre os valores apresentados, dois valores cuja multiplicação resulta em 24. 


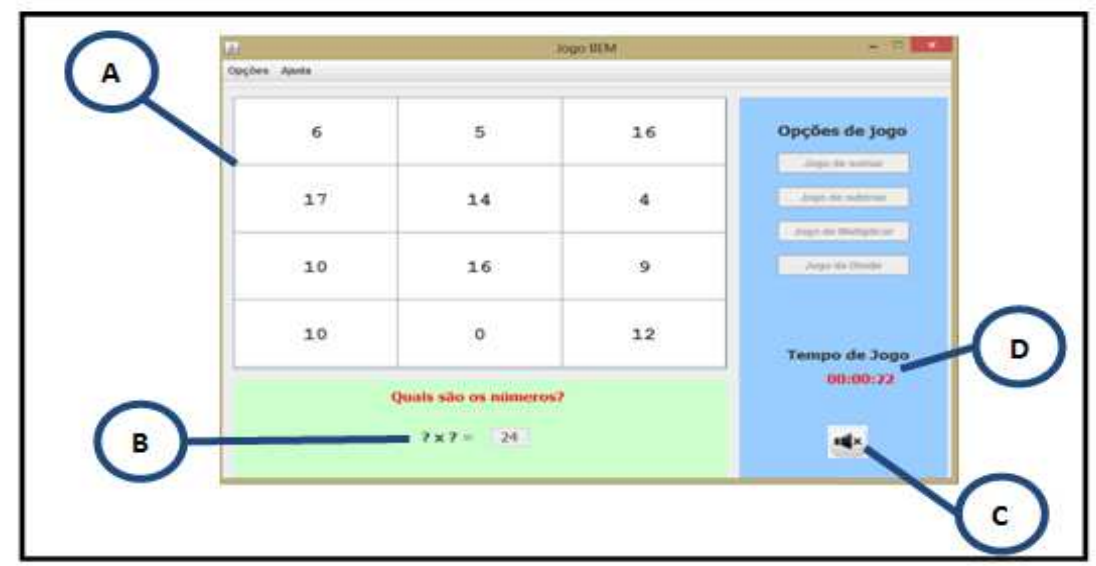

Figura 1. Tela de execução do jogo de multiplicação. Fonte: Própria, 2017

Os níveis e subníveis de dificuldade são definidos, respectivamente, pela quantidade de células do tabuleiro e pela faixa de valores das células do tabuleiro. $\mathrm{O}$ software BEM possui alguns recursos de gamefication que buscam dar o aspecto lúdico à ferramenta. Um destes recursos é a utilização do cronômetro (Figura 1- D), que visa estimular o estudante no desenvolvimento da capacidade de resolução dos exercícios de forma mais rápida, necessitando, desta forma, de um intervalo menor de tempo para alcançar o fim do jogo. Outra funcionalidade do software é a possibilidade da ativação ou desativação da síntese de voz a qualquer momento (Figura $1-\mathrm{C}$ ).

O software BEM é totalmente acessível a pessoas com DV através da síntese e do reconhecimento de voz. O reconhecimento de voz é realizado através de comandos pré-definidos associados a cada funcionalidade do software. Por exemplo, o usuário pode ditar a palavra "SOMAR" e será redirecionado ao jogo que envolve operações de soma. O reconhecimento de voz é baseado em uma gramática, na qual são definidas as palavras e sentenças aceitas pelo software como comandos (Quadro 1).

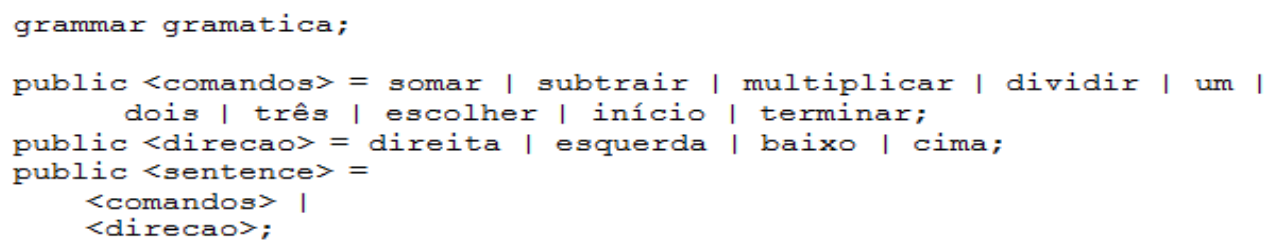

Quadro 1. Gramática com comandos aceitos pelo jogo BEM. Fonte: Própria, 2017

Para todas as funcionalidades do software, o usuário pode utilizar o teclado e/ou mouse para o seu acionamento. Além destes dois tipos de interação, o usuário pode utilizar a fala para comandar o software. Desta forma, supondo que os comandos de fala são dados, geralmente, por pessoas com DV, cada ação do usuário, através da fala ou teclado, está relacionada ao ato de o software produzir uma mensagem sonora para que o usuário permaneça sempre ciente do que ele está realizando no software. Para navegação no tabuleiro, por exemplo, o usuário pode utilizar quatro palavras (cima, baixo, direita e esquerda) para movimentar o cursor pelas células do tabuleiro. Desta forma, como mensagem de retorno, o software dita o valor numérico que consta na respectiva célula. Além da fala, o usuário pode utilizar as teclas de navegação do teclado ou até mesmo o mouse para selecionar os devidos valores da operação dada.

No Quadro 2, são listadas as funcionalidades do software BEM que podem ser acessadas através de comandos vocais, com as suas respectivas descrições detalhadas, a palavra que deve ser dita para acioná-las e as mensagens correspondentes narradas pelo 
VI Congresso Brasileiro de Informática na Educação (CBIE 2017)

Anais do XXVIII Simpósio Brasileiro de Informática na Educação (SBIE 2017)

software como retorno das ações do usuário.

\begin{tabular}{|c|c|c|c|}
\hline $\begin{array}{l}\text { Funciona- } \\
\text { lidade }\end{array}$ & Descrição detalhada da funcionalidade & $\begin{array}{l}\text { Reconhe- } \\
\text { cimento }\end{array}$ & Síntese \\
\hline $\begin{array}{l}\text { Início do } \\
\text { jogo }\end{array}$ & $\begin{array}{l}\text { O usuário pode retornar, a qualquer } \\
\text { momento, à tela inicial do jogo. }\end{array}$ & Início & $\begin{array}{l}\text { "Olá, seja bem-vindo a tela inicial do jogo } \\
\text { BEM. Para informações gerais do jogo } \\
\text { pressione a tecla F1. Para ativar o } \\
\text { reconhecimento de fala pressione F3." }\end{array}$ \\
\hline $\begin{array}{l}\text { Finalizar } \\
\text { jogo }\end{array}$ & $\begin{array}{l}\text { Durante a execução do jogo, o usuário } \\
\text { pode solicitar a sua finalização. }\end{array}$ & Terminar & "Saiu. Obrigado". \\
\hline $\begin{array}{l}\text { Iniciar jogo } \\
\text { de somar }\end{array}$ & $\begin{array}{l}\text { O usuário, estando na tela inicial do jogo, } \\
\text { pode solicitar a inicialização do jogo de } \\
\text { somar. }\end{array}$ & Somar & $\begin{array}{l}\text { "Você selecionou o jogo de somar. } \\
\text { Pressione ou fale: um para o nível fácil, } \\
\text { dois para o nível médio e três para o nível } \\
\text { difícil. Fale ou pressione a opção desejada." }\end{array}$ \\
\hline $\begin{array}{l}\text { Iniciar jogo } \\
\text { de subtrair }\end{array}$ & Idem para o jogo de subtrair. & Subtrair & $\begin{array}{l}\text { "Você selecionou o jogo de subtrair. } \\
\text { Pressione ou fale um para o nível fácil, dois } \\
\text { para o nível médio e três para o nível difícil. } \\
\text { Fale ou pressione a opção desejada." }\end{array}$ \\
\hline $\begin{array}{l}\text { Iniciar jogo } \\
\text { de } \\
\text { multiplicar }\end{array}$ & Idem para o jogo de multiplicar. & Multiplicar & $\begin{array}{l}\text { "Você selecionou o jogo de multiplicar. } \\
\text { Pressione ou fale um para o nível fácil, dois } \\
\text { para o nível médio e três para o nível difícil. } \\
\text { Fale ou pressione a opção desejada." }\end{array}$ \\
\hline $\begin{array}{l}\text { Iniciar jogo } \\
\text { de dividir }\end{array}$ & Idem para o jogo de dividir. & Dividir & $\begin{array}{l}\text { "Você selecionou o jogo de dividir. } \\
\text { Pressione ou fale um para o nível fácil, dois } \\
\text { para o nível médio e três para o nível difícil. } \\
\text { Fale ou pressione a opção desejada." }\end{array}$ \\
\hline $\begin{array}{l}\text { Selecionar } \\
\text { nível fácil }\end{array}$ & $\begin{array}{l}\text { Ao solicitar a inicialização de um dos } \\
\text { quatro jogos, o usuário pode selecionar o } \\
\text { nível fácil. }\end{array}$ & $\mathrm{Um}$ & $\begin{array}{l}\text { "Você selecionou o nível fácil. Pressione } \\
\text { enter para confirmar." }\end{array}$ \\
\hline $\begin{array}{l}\text { Selecionar } \\
\text { nível médio }\end{array}$ & $\begin{array}{l}\text { Ao solicitar a inicialização de um dos } \\
\text { quatro jogos, o usuário pode selecionar o } \\
\text { nível médio. }\end{array}$ & Dois & $\begin{array}{l}\text { "Você selecionou o nível médio. Pressione } \\
\text { enter para confirmar." }\end{array}$ \\
\hline $\begin{array}{l}\text { Selecionar } \\
\text { nível difícil }\end{array}$ & $\begin{array}{l}\text { Ao solicitar a inicialização de um dos } \\
\text { quatro jogos, o usuário pode selecionar o } \\
\text { nível difícil. }\end{array}$ & Três & $\begin{array}{l}\text { "Você selecionou o nível difícil. Pressione } \\
\text { enter para confirmar." }\end{array}$ \\
\hline $\begin{array}{l}\text { Mover } \\
\text { cursor para } \\
\text { cima }\end{array}$ & $\begin{array}{l}\text { Durante a execução do jogo, o usuário } \\
\text { pode solicitar que o cursor do tabuleiro } \\
\text { seja movido para cima. Quando possível, } \\
\text { o cursor é movido uma célula acima e é } \\
\text { sintetizada a mensagem informando o } \\
\text { valor que consta na célula que se encontra } \\
\text { o cursor. }\end{array}$ & Cima & $\begin{array}{l}\text { Mensagem informando o valor que consta } \\
\text { na célula que se encontra o cursor. }\end{array}$ \\
\hline $\begin{array}{l}\text { Mover } \\
\text { cursor para } \\
\text { baixo }\end{array}$ & $\begin{array}{l}\text { Solicitação de mover o cursor para baixo. } \\
\text { Quando possível, o cursor é movido uma } \\
\text { célula abaixo e é sintetizada a mensagem } \\
\text { informando o valor que consta na célula } \\
\text { que se encontra o cursor. }\end{array}$ & Baixo & $\begin{array}{l}\text { Mensagem informando o valor que consta } \\
\text { na célula que se encontra o cursor. }\end{array}$ \\
\hline $\begin{array}{l}\text { Mover } \\
\text { cursor para } \\
\text { direita }\end{array}$ & $\begin{array}{l}\text { Solicitação de mover o cursor do tabuleiro } \\
\text { para direita. Quando possível, o cursor é } \\
\text { movido uma célula a direita e é sintetizada } \\
\text { a mensagem informando o valor que } \\
\text { consta na célula que se encontra o cursor. }\end{array}$ & Direita & $\begin{array}{l}\text { Mensagem informando o valor que consta } \\
\text { na célula que se encontra o cursor. }\end{array}$ \\
\hline
\end{tabular}




\begin{tabular}{|c|l|l|l|}
\hline $\begin{array}{c}\text { Mover } \\
\text { cursor para } \\
\text { esquerda }\end{array}$ & $\begin{array}{l}\text { Solicitação de mover o cursor para } \\
\text { esquerda. Quando possível, o cursor é } \\
\text { movido uma célula a esquerda e é } \\
\text { sintetizada a mensagem informando o } \\
\text { valor que consta na célula que se encontra } \\
\text { o cursor. }\end{array}$ & $\begin{array}{l}\text { Mensagem informando o valor que consta } \\
\text { na célula que se encontra o cursor. }\end{array}$ \\
\hline $\begin{array}{c}\text { Selecionar } \\
\text { célula do } \\
\text { tabuleiro }\end{array}$ & $\begin{array}{l}\text { Selecionar uma célula do tabuleiro para } \\
\text { definir como um possível operando da } \\
\text { operação sugerida para resolução. }\end{array}$ & Selecionar & $\begin{array}{l}\text { "Você selecionou o valor X". Sendo Xo o } \\
\text { valor que consta na célula. }\end{array}$ \\
\hline
\end{tabular}

Quadro 2. Funcionalidades assistidas pelo reconhecimento de voz. Fonte: Própria, 2017

\section{Aplicação de testes e Resultados parciais}

Desde a versão inicial do jogo BEM, são realizados testes juntamente com aplicações de questionários a fim de validar a ferramenta e também apresentá-la ao público-alvo. Com a versão 1.0 da ferramenta, foram aplicados questionários específicos com a finalidade de avaliação das funcionalidades, das modalidades de interação (i.e. síntese de voz e teclado), da interface visual, entre outros aspectos. Os resultados desta etapa foram publicados por Santos e outros (2016).

Com a versão mais atual do BEM, apresentada neste trabalho, e com a inclusão das funcionalidades de reconhecimento de voz, foram realizados testes preliminares com propósito da validação parcial da ferramenta com a inserção da nova modalidade de interação. Essa etapa objetivou a avaliação da utilização da ferramenta apenas com a utilização das funcionalidades de reconhecimento de fala. Para isso, foi elaborado um questionário específico para a modalidade de reconhecimento de fala, composto por dez tópicos, seguindo um padrão das alternativas com 5 opções (Discordo fortemente, Discordo parcialmente, Indiferente, Concordo parcialmente e Concordo totalmente).

A ferramenta foi avaliada por 6 pessoas que se dispuserem a participar do processo de validação do BEM. Esse processo teve início com a utilização da ferramenta pelo participante voluntário e, logo em seguida, com a respostado questionário. Ao final do questionário, as pessoas podiam expor suas opiniões em relação aos pontos positivos e negativos, através de questões abertas, além de relatar alguma sugestão para a ferramenta. Os questionamentos objetivaram exclusivamente a avaliação da funcionalidade de reconhecimento de voz acoplada à ferramenta BEM. Os principais aspectos avaliados foram: velocidade de resposta, qualidade do reconhecimento das palavras, verificação de possíveis falhas devido a ruídos no ambiente de teste e possível utilização do software utilizando os dois modos de interação (voz e teclado).

Um dos pontos avaliados foi a velocidade de resposta do sistema com a utilização do reconhecimento de voz. Foi exposta a seguinte afirmação no questionário: "A velocidade de resposta é adequada". Neste aspecto, as respostas obtidas se dividiram em apenas duas alternativas: concordo parcialmente e concordo fortemente, ficando 50\% para cada. Outra afirmativa apresentada foi: "O software ignorou uma palavra em minha pronúncia". Para este ponto, 2 (duas) pessoas marcaram a opção discordo fortemente, 3 (três) pessoas marcaram a opção discordo parcialmente e apenas 1 (uma) assinalou concordo fortemente.

Embora o objetivo do questionário tenha sido a avaliação do reconhecimento de voz na ferramenta BEM, também se avaliou a possibilidade de utilização do software com as 2 modalidades de interação, voz e teclado, em paralelo. Para este ponto, utilizou 
o enunciado "É possível a utilização da fala e comandos de teclado em paralelo". As respostas obtidas foram: 2 (duas) para a opção discordo parcialmente, 1 (uma) para concordo parcialmente e 3 (três) para concordo totalmente. Outro ponto avaliado foi a capacidade de facilitação da utilização da ferramenta com a funcionalidade de reconhecimento de voz com a afirmativa: "O reconhecimento de voz facilita a utilização do software". Neste aspecto, as respostas se dividiram em concordo parcialmente e concordo fortemente, sendo uma para primeira opção e cinco marcações para a segunda.

A partir da avaliação dos resultados dos questionários, percebe-se que a atual versão da ferramenta com o reconhecimento de fala já atende às expectativas do público-alvo, visto que é possível a utilização do mesmo, de forma facilitada, apenas com o uso da fala. Apesar da obtenção de resultados positivos, durante a aplicação dos testes, foram identificadas algumas sugestões de melhorias para a funcionalidade de reconhecimento, como, por exemplo, uma possível alteração do motor de reconhecimento de voz. Isto foi exposto por um dos voluntários, argumentado pela expressão: "Em alguns momentos, necessitei pronunciar a mesma palavra mais de uma vez. Por isso, sugiro a utilização de uma tecnologia mais aprimorada".

\section{Conclusões}

Desde a versão inicial do jogo BEM, é perceptível a sua potencialidade no processo de ensino e aprendizagem da matemática. Este software, além de possuir a virtude de contribuir para a evolução do processo educacional das quatro operações básicas da matemática, se mostra como uma ferramenta tecnológica que concretiza a inclusão de pessoas com deficiência visual na era tecnológica, oportunizando a utilização de um programa de computador que visa o avanço cognitivo pessoal, através dos sentidos remanescentes, como o tato, a fala e a audição.

Apesar de este trabalho ter como foco a apresentação da versão do BEM que trata das operações básicas da matemática de forma isolada, mais especificamente a versão com suporte ao reconhecimento de voz/fala, há outra versão sendo implementada que objetiva a assistência no processo educacional das expressões aritméticas, ou seja, as operações matemáticas sendo tratadas em paralelo.

Atualmente, o BEM não dá suporte total para a execução de todas as funcionalidades através de comandos vocais, entretanto isto não limita a sua utilização pelo público DV. Como listado na seção anterior, com as funcionalidades que são amparadas pelo reconhecimento de voz/falar, é possível a sua utilização sem qualquer prejuízo ou impossibilidade do aproveitamento do principal intuito do software, que é a prática de exercícios matemáticos de forma dinâmica.

Como exemplo de funcionalidade que não é amparada pelo reconhecimento de voz, pode-se citar a navegação pelos menus. Com isso, almeja-se como trabalhos futuros a implementação do suporte total do reconhecimento de voz no BEM, distribuição do software em instituições de ensino e realização de testes com o públicoalvo, a fim de avaliar, entre outros aspectos, a qualidade do reconhecimento de voz e a efetividade da aplicação do software BEM como recurso pedagógico na sala de aula. Além disso, pretende-se ampliar a aplicação de testes, envolvendo docentes e discentes, a fim da real avaliação da potencialidade educacional da ferramenta. 
VI Congresso Brasileiro de Informática na Educação (CBIE 2017)

Anais do XXVIII Simpósio Brasileiro de Informática na Educação (SBIE 2017)

\section{Referências}

ALVES, C. P. (2015). "Fala Brasil: Reconhecimento de Voz para o Português Brasileiro". Disponível em: <http://www.laps.ufpa.br/falabrasil/>. Acesso feito em: Setembro/2015.

ARAÚJO, S. M. D. (1997). “O Jogo Simbólico numa Proposta Pedagógica para o deficiente Visual". Revista do Instituto Benjamin Constant, Rio de Janeiro.

ARAUJO, M. V., LOPES, E. (2013). "Sala de recursos e contra turno escolar: entendendo as diferenças". VIII Encontro da Associação Brasileira de Pesquisadores em Educação Especial. Londrina.

CLOUDGARDEN. (2015). Disponível em:<http://www.cloudgarden.org/JSAPI/>. Acesso feito em: Outubro/2015.

CMUSPHINX. (2015). "Sphinx 4". Disponível em: <http://cmusphinx.sourceforge.net/wiki/sphinx4:webhome>. Acesso feito em: Setembro/2015.

COLOMBO, F. B., KOMORI, F. S.,TORRES, T. B. (2013). "Reconhecimento de fala". Escola Politécnica da Universidade de São Paulo. São Paulo.

CUNHA, E. E. (2007). "JogaVOX: Ferramenta e Estratégias para Construção de Jogos Educacionais para Deficientes Visuais”. Dissertação (Mestrado em Informática) Instituto de Matemática, Universidade Federal do Rio de Janeiro, Rio de Janeiro.

GARCIA, S. C. (2006). "Objetos de aprendizagem: investindo na mediação digital do conhecimento". VII Encontro do Círculo de Estudos Linguísticos do Sul - CELSUL, UCPel (Universidade Católica de Pelotas) e UFPel (Universidade Federal de Pelotas), Pelotas - RS.

IBGE. (2010). “Censo 2010”. Acesso em: 1/3/2017, Disponível em: $<$ http://cod.ibge.gov.br/234d0>.

IBM VIAVOICE SDK. (2015). Disponível em: <http://ibm-viavoice-sdk-forwindows.software.informer.com/ > . Acesso feito em: Outubro/2015.

IEEE. (2002). "Standard for Learning Object Metadata". Acesso em: 3/3/2017, em: http://ieeexplore.ieee.org/servlet/opac?punumber $=8032$

LIMA, M. R., SILVA. N. I., ARAÚJO R. K. S. \&ABRANCHES S. (2007). "O impacto do uso das tecnologias no aprendizado dos alunos do ensino fundamental".UFPEUniversidade Federal de Pernambuco, Recife - PE.

MACEDO, R. S.; SENA, C. P. P.; SANTOS, A. J. O. S.; FERNANDES, A. L. B.; PINTO, G. R. P. R. "A utilização de jogos na educação matemática para crianças com deficiência visual e videntes". In: Escola Regional de Computação Bahia Alagoas - Sergipe, 2015, Salvador. WTICGBASE, 2015.

OLIVEIRA, A. A. S., \& LEITE, L. P. (2007). "Construção de um sistema educacional inclusivo: um desafio político-pedagógico" . Ensaio: Avaliação e Políticas Públicas em Educação, 15(57), 511-524. Acesso em: 2/3/2017 em: https://dx.doi.org/10.1590/S0104-40362007000400004

OLIVEIRA, C., MOURA, S. P., \&SOUSA E. R. (2015). "TIC'S na Educação: A utilização das tecnologias da informação e comunicação na aprendizagem do aluno". Revista Eletrônica do Curso de Pedagogia da PUC Minas - Pedagogia em Ação. Belo Horizonte-MG.

RESENDE, T. R. M. (2007). "Política estadual de atendimento a alunos com deficiência visual na cidade de São Paulo: a percepção do usuário”. Dissertação de mestrado em educação. Universidade Cidade de São Paulo - UNICID. São Paulo. 
SANCHES, I. (2011). "Do aprender para fazer ao aprender fazendo: as práticas de Educação inclusiva na escola". Rev. Lusófona de Educação [online], n.19, pp.135156. ISSN 1645-7250.

SANCHEZ, J. N. G. (2004). Dificuldades de Aprendizagem e Intervenção Psicopedagógica. Porto Alegre: Artmed.

SANTANA, K. C., SENA, C. P. P., SANTOS, A. J. O., FERNANDES, A. L. B., \& MACEDO. R. S. (2016). "Blinds, Basic Education: um jogo multidisciplinar para a educação básica de crianças com deficiência visual e videntes”. In: Escola Regional de Computação Bahia - Alagoas - Sergipe. WInDBASE.

SANTOS, A. J. O. S., SENA, C. P. P., MACEDO, R. S., SANTANA, K. C., \& FERNANDES, A. L. B. (2016). "Análise do uso do Objeto de Aprendizagem BEM no processo educacional de pessoas com deficiência visual e videntes". Escola Regional de Computação Bahia - Alagoas - Sergipe. WTICGBASE. Maceió-AL.

SENA, C. P. P. (2006). "Desenvolvimento de interfaces multimodais com ênfase no uso da voz". Dissertação de mestrado em redes de computadores. Universidade Salvador - UNIFACS. Salvador - BA.

SILVA, M, O. E. (2011). "Educação Inclusiva: um novo paradigma de Escola". Rev. Lusófona de Educação [online]. N.19, pp.119-134. ISSN 1645-7250. 